TechnoLEARN: An International Journal of Educational Technology

TechnoLEARN: 9(2): 101-109, December 2019

DOI: 10.30954/2231-4105.02.2019.7

(O2019 New Delhi Publishers. All rights reserved

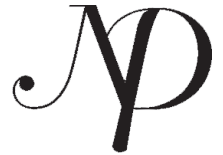

\title{
A Comparative Study of the Adjustment of the Female and Male Students Studying at Higher Secondary Level
}

\section{Lalima" and Sheetal Prasad}

Department of Education, Babsaheb Bhimrao Ambedkar University, Lucknow, Uttar Pradesh, India

*Corresponding author: dr.lbbau@gmail.com

\begin{abstract}
The higher secondary level is considered very crucial stage at educational level. The students are at later adolescent stage trying to cope up with their psychological changes and their changing social roles. They have lot of stress for the indefinite future. This causes various adjustment problems for the students. These adjustment issues are different for both boys and girls as social norms, social stereotypes and social roles and expectations is different for both the genders and similarly the ways of solving adjustment problems is also different for both the boys and girls. The present paper compares the adjustment level of male and female students studying at higher secondary level.
\end{abstract}

Keywords: Adolescent, adjustment, health adjustment, home adjustment, emotional adjustment and social adjustment

The higher secondary level is considered very crucial stage at educational level due to many reasons firstly it is the stage which is important for career development of the students, the choices made at this stage and the efforts made to grasp the opportunities at right time build the future life of the students, secondarily after this stage students are considered as adult in constitutional terms, they are considered as responsible citizens of nation capable of participating in political activities of country so they need to develop the analytical and decision making capabilities for performing their duties in a justified way and play important role in fighting with social taboos, thirdly at this stage students are at later adolescent period and face many of psychological stresses, complexes and they have to resolve various value conflicts positively. All these crucial roles make this stage very important and it is very 
p

Lalima and Prasad

necessary that students of this stage are well adjusted individuals with balanced personalities and high emotional quotient. It is necessary that they are well adjusted with their family members, with society and above all well adjusted with their own physical and inner self.

\section{Statement of the problem}

A comparative study of the adjustment of female and male students studying at secondary level.

\section{Operational definitions}

\section{Adjustment}

The adjustment refers to the capability of an individual in bringing a balance between its need and his/her circumstances. It is the behavioural process and struggle of an individual to survive, maintain equilibrium and try to be happy in his environment.

In the present study adjustment of the students have been considered in four dimensions.

Home adjustment- home adjustment refers to the balance between needs and demands and family circumstances, it refers to the adaptation and satisfaction with the family atmosphere, good relations with family members including parents and sibling, understanding and identifying with family values and norms and also feeling balanced with financial conditions of family. A person who is properly adjusted in his home is willing to spend time at home, feels peace and happiness while at home and is ready to balance his individual needs and needs of his family. Home adjustment is highly influential in shaping the personality. It depends not only on the individual but also on his family and parents.

Health adjustment- it is the continuous process to adapt to the development process, understanding and accepting physical self and managing health issues in a suitable way. Health adjustment is adapting to one physical structure and conditions. Proper knowledge and awareness of biological conditions of the body and different threats to it improves health adjustment.

Social adjustment- social adjustment means the success with which an individual adjust to other people and groups with which they are indentified. Socially well adjusted individuals deal diplomatically with others, both friends and strangers due to that other's attitude towards them is also favourable. Socially well adjusted beings have favourable social attitudes such as willingness to help others, they are not self bound. The criterion of social adjustment is overt performances, adjustment to other social groups, favourable social attitudes and personal adjustment.

Emotional adjustment- refers to the capability of an individual to understand his emotional self, balanced expression of emotions and marinating a harmony in emotional system. An 
A Comparative Study of the Adjustment of the Female and Male Students Studying... . $\supset$

emotionally adjusted being is aware of his emotions, is able to manage his emotions and knows the constructive ways to express his emotions.

Higher secondary level- higher secondary level means students studying at class eleventh and twelfth. In the study students of class eleventh are included. Generally the students of higher secondary level are of age group 16-18 and are in later adolescent stage.

\section{Need of the study}

Only an individual who is able to maintain balance between his needs and social and family values and demands, who feel inner peace, who has constructive ways to deal with his emotions can lead a satisfactory life and can be a productive member of the society. To properly utilize our human resource we need them to be in complete harmony with the different aspects of their personality physical, mental and emotional ready to face the challenges of life in a constructive way. As discussed above higher secondary level is important as it shoulders the responsibility to provide mature, responsible members to the society well trained in life skills and ready to part their part in the society. If students of this age will be maladjusted the strength of our society will be weakened and we will in lack of youth force to lead the nation so it is important to study the adjustment level of male and female students and provide them proper guidance in areas where help is needed.

\section{Objectives}

1. To study adjustment of male students studying in class eleven.

2. To study adjustment of female students studying in class eleven.

3. To compare the adjustment in different areas of male and female students studying in class eleven.

\section{Methodology}

The survey method was used to collect data in the present study.

\section{Tool}

A standardized tool was used for studying the adjustment.

Indian Adaptation of Belly's Adjustment inventory by Sharma Lalita. The tool contains eighty items divided into four dimensions-

Home adjustment, health adjustment, social adjustment and emotional adjustment.

Sample- the study was conducted on the 100 students of Lucknow city studying at higher secondary level. 
p

Lalima and Prasad

Sampling - sampling was done at two stages. At stage one; schools were selected through random sampling total four schools were selected for the data collection. In selected schools intact class was used for data collection.

\section{RESULTS AND DISCUSSION}

\section{Objective 1}

To study adjustment of male students studying in class eleven.

For this study the scores of male students were calculated separately in all the four areas of adjustment. The result is shown in table 1

Table 1: Showing scores of Male students in four areas of adjustment

\begin{tabular}{ccccccc}
\hline \multirow{2}{*}{ S1. No. } & Areas & \multicolumn{5}{c}{ Number of students } \\
\cline { 3 - 7 } & & Very good & Good & Average & Unsatisfactory & Very unsatisfactory \\
\hline 1 & Home adjustment & 32 & 11 & 12 & 01 & 00 \\
2 & Heath Adjustment & 09 & 17 & 26 & 03 & 01 \\
3 & Social Adjustment & 04 & 29 & 22 & 00 & 00 \\
4 & Emotional Adjustment & 00 & 04 & 50 & 02 & 00 \\
\hline
\end{tabular}

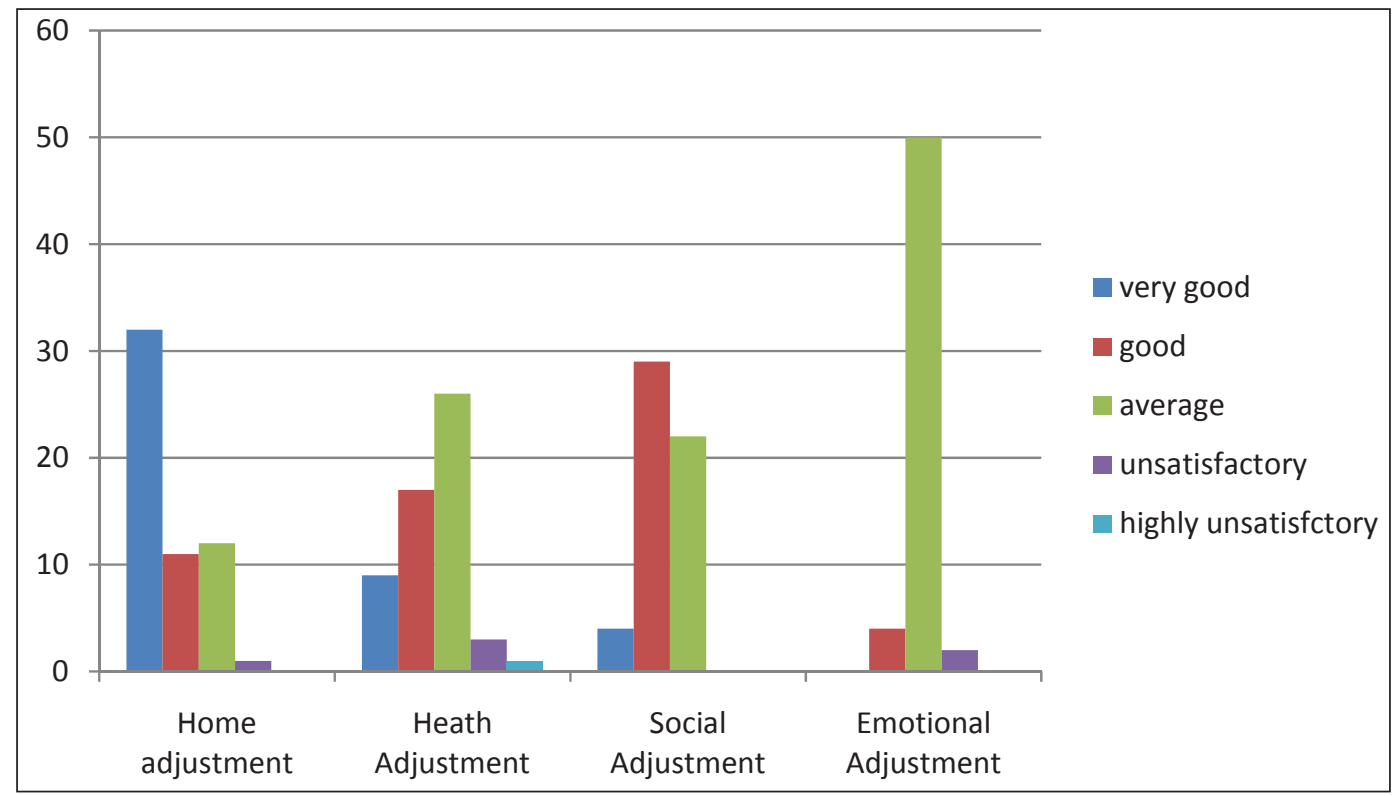

Graph 1: Showing scores of Male students in four areas of adjustment 
A Comparative Study of the Adjustment of the Female and Male Students Studying... . $\supset$

The table and graph clearly shows that home adjustment of Male student is good nearly 32 out of 56 students have very good home adjustments. Only one male scores lie in the unsatisfactory category. All the male students either have average or above average home adjustment. Boys are well adjusted with their families and have managed to maintain balance between their family circumstances and their needs.

In health adjustment areas nearly fifty percent males have average adjustment, none have very good adjustment in this area where as unsatisfactory scores have shown by only three of the male students. This shows that male students are not very well adjusted with their physical self and health conditions. As adolescent period involves lot of hormonal changes and an individual's body is in a process to be ready to bear the responsibility of an adult so anxiety and confusion related to health issues is very normal in this period. The curiosity and lack of satisfaction with one's health is depicted in the result

In social adjustments twenty nine male students have good social adjustment, only two show unsatisfactory adjustments in this area. These results show that male students are able to adjust in social groups and gatherings and are able to balance their individual needs and social norms and social demands.

In emotional adjustment fifty students have average adjustment with none of the scores reaching in the area of very good adjustment and two of them show that they have unsatisfactory emotional adjustment. Emotional adjustment refers to adjusting, understanding and bringing balance between one's emotions. The result shows that this area requires improvement.

\section{Objective 2}

To study adjustment of female students studying in class eleven.

For finding out the home, health, social and emotional adjustment of female students the score $\sin$ these area was calculated and presented by a graph.

Table 2: Showing scores of Female students in four areas of adjustment

\begin{tabular}{ccccccc}
\hline \multirow{2}{*}{ S1. No. } & Areas & \multicolumn{5}{c}{ Number of students } \\
\cline { 3 - 7 } & & Very good & Good & Average & Unsatisfactory & Very unsatisfactory \\
\hline 1 & Home adjustment & 20 & 11 & 08 & 03 & 01 \\
2 & Heath Adjustment & 02 & 14 & 20 & 03 & 05 \\
3 & Social Adjustment & 03 & 19 & 22 & 00 & 00 \\
4 & Emotional Adjustment & 00 & 03 & 32 & 09 & 00 \\
\hline
\end{tabular}




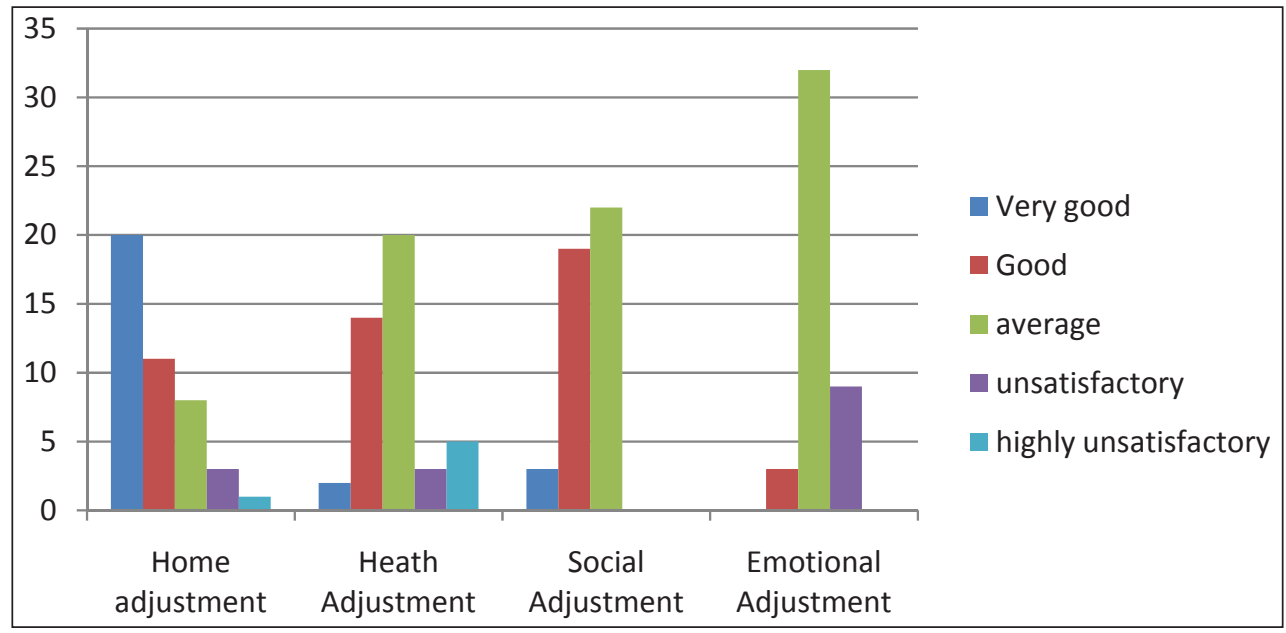

Graph 2: Showing scores of Female students in four areas of adjustment

The scores show that female students have good home adjustment. Only four females have below average adjustment in this area. Fifty percent students have very good home adjustment. They are able to maintain a harmony with home atmosphere, family finance and have good relationships with their siblings.

In area of heath adjustment most of the female students have good and average adjustments where as eight females show unsatisfactory adjustment. The results reflect that students need proper health guidance services as our society is very traditional and there is no provision for a proper sex education. The student's curiosities regarding their health issues, changes in their body are either left unanswered or are solved by media and peer groups. This may lead to partial or incorrect knowledge and maladjustment.

For social adjustment all the female students scored average or above average scores. Almost fifty percent of students showed average social adjustments .social adjustment nowadays is highly influenced by technological adjustment. As adolescent are indulging more with information and communication technologies their social adjustment, capacity to adjust in different social groups and adapting to social conditions in adversely affected. Moreover this study is done in city where families are more isolated and nearly indulged in social gathering with their neighbours or local community $\mathrm{n}$ regular basis. These are the reason why only three female students show very good social adjustment.

Thirty two females show average emotional adjustment and nine show unsatisfactory emotional adjustment. None of the female scores on extremes i.e. very good or very unsatisfactory. The female emotional adjustment needs to be improved and they need strategies to improve their emotional quotient. 


\section{Objective 3}

To compare the adjustment in different areas of male and female students studying in class eleven. For this objective mean scores of male and female students studying in class eleventh were calculated in home, health, social and emotional adjustment areas. The mean scores are depicted in table 3 and a comparative picture is presented in graph 3.

Table 3: Showing mean scores of female and male students in four areas of adjustment

\begin{tabular}{ccc}
\hline Areas & \multicolumn{2}{c}{ Mean } \\
\cline { 2 - 3 } & Male & Female \\
\hline Home adjustment & 5.41 & 6.50 \\
Heath Adjustment & 5.30 & 6.47 \\
Social Adjustment & 7.89 & 8.75 \\
Emotional Adjustment & 8.37 & 10.25 \\
\hline
\end{tabular}

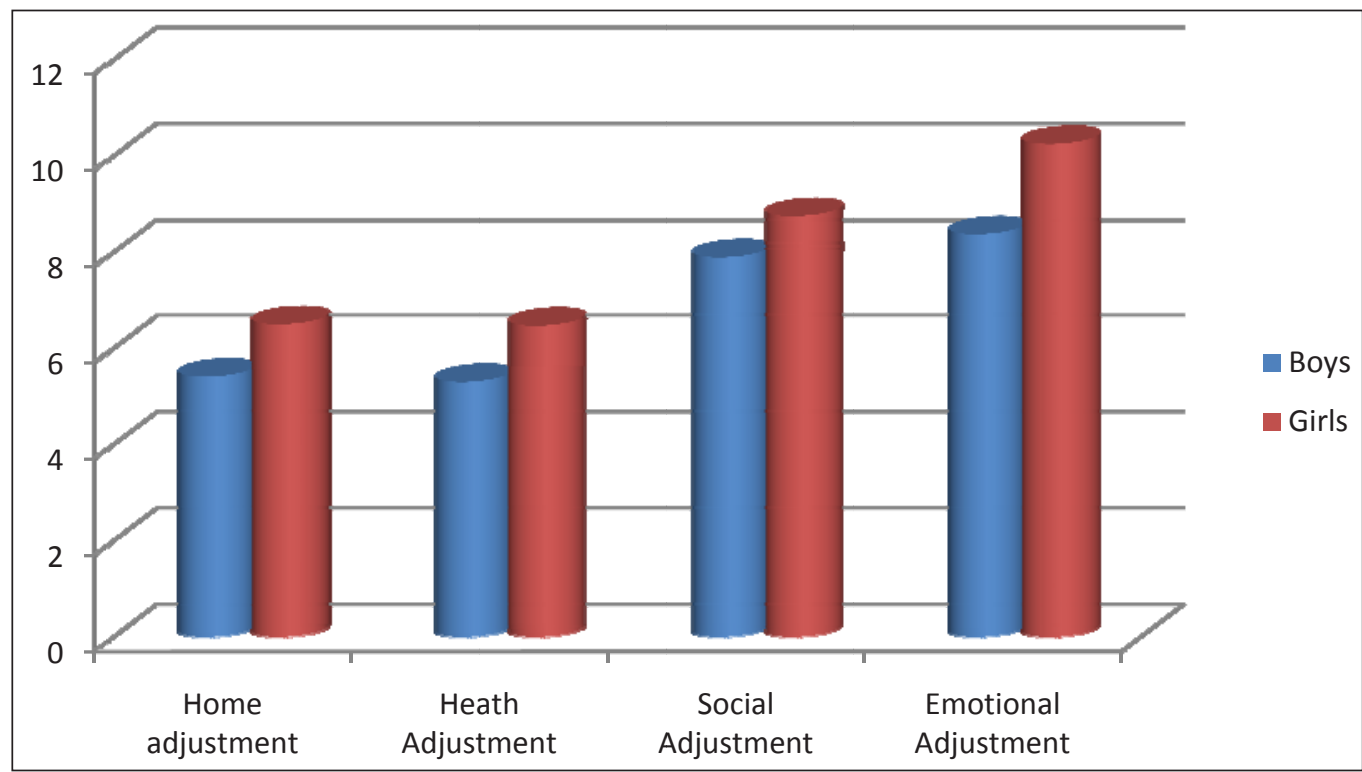

Graph 3: Showing comparative mean scores of female and male students in four areas of adjustment

The table 3 and graph clearly depict that in relation to mean scores female students are better adjusted than their counterparts in home, social health and emotional adjustments. This result contradicts the study done by Thanikaive, M. \& Priya, K. (2016) to study the problems of adjustment in school going adolescent students. The adjustment of students was studied in following areas-home, social, emotional, health and education. The result of this study revealed 
p

Lalima and Prasad

that adjustment of male students was better than female students. The result of study done by Gehlawat, Manju. (2011) support the result of this study. In her study on adjustments of high school students in relation to their gender reported that there was no significant difference in adjustment of male and female students in social, emotional and educational adjustments but in context with mean scores that emotional, social and educational adjustment of boys is less than girls. Similar result was found by Bhagat Puja (2016) in her study where she compared the adjustment of secondary boys and girls. Results showed that girls were found more adjusted than girls. Girls were found emotionally and educationally more adjusted than boys. Boys were found socially more adjusted than girls. Mahmood \& Iqbal (2015) in their study revealed that female students have more psychological adjustment than male students Ghatak Rakhi (2018). In her study on home adjustment of adolescents showed that female adolescents have higher home adjustment capacities than male adolescents.

\section{CONCLUSION}

1. Home adjustment of both female and male students of higher secondary level is good.

2. The social and health adjustments of both female and male students of higher secondary are of moderate level.

3. Emotional adjustment is average for both male and female.

4. Female students are comparatively better adjusted than their male counterparts on home, health, social and emotional adjustment.

\section{IMPLICATIONS}

The health adjustments of male and female higher secondary students need to be improved. We need a proper well planned health counselling for the students so that they can adapt to the changes they are undergoing physically and mentally. They need to be educated regarding health issues;

* We need proper strategies to enhance emotional intelligence of the students. The students need help from their teachers and parents to understand and manage their emotions so that they can feel harmony at emotional aspect;

* The students should be given platforms for social interchange and opportunities to be involved in social activities so that can be well trained in social values and social skills. This can be done through community involvement, community work and integrating methods like collaborative and cooperative learning;

* A comprehensive programme with a joint effort of parents and teachers need to be initiated for improving the overall adjustment level of adolescent students. 
A Comparative Study of the Adjustment of the Female and Male Students Studying... . $\$

\section{REFERENCES}

Baron, A. Robert \& Misra, Girishwar. (5 ${ }^{\text {th }}$ Edition). Psychology. Delhi: Pearson India Educational Services Pvt Ltd.

Berk, E. Laura. (9 $9^{\text {th }}$ Edition) Child Development. Delhi: Pearson India Educational Services Pvt Ltd.

Bhagat Puja. 2016. Comparative study of adjustment among secondary boys and girls. International Journal of Applied Research, 2(7): 91-95.

Gehlawat, Manju. 2011. A study of adjustment of among high school students in relation to their gender. International Referred Journal, 3(33): 14-15.

Ghatak Rakhi. 2018. A study on Home Adjustment of Adolescents. International Journal of Scientific Development and Research, 3(8): 204-206.

Hurlock, B. Elizabath. (6 $6^{\text {th }}$ Edition). Child Development. New Delhi: McGraw Hill Education (India) Private Limited.

Mahmood Khalid and Iqbal, M.M. 2015. Psychological adjustment and academic achievement among adolescents. Journal of Education and Practice, 6(1): 39-42.

Ormod, Ellis, Jeanne. Essentials of Educational Psychology. Delhi: Pearson India Educational Services Pvt Ltd.

Sharma Lalita. Manual for Indian Adaptation of Bell's adjustment inventory.

Thanikaive, M. and Priya, K. 2016. Adjustment problems among school going adolescent students. EPRA International Journal of Multidisciplinary research, 2(8): 1-3. 
